\title{
The reasoning of mining methods parameters toward development of the apatite-nepheline ore deposits based on results of forecast of massif stress state
}

\author{
Ilya Bagautdinov ${ }^{1 *}$, Anton Kuranov ${ }^{1}$, Nikita Belyakov ${ }^{1}$ and Anatoly Streshnev ${ }^{2}$ \\ ${ }^{1}$ Mining University, Saint-Petersburg, Russia. \\ 2،Apatit', Kirovsk, Russia.
}

\begin{abstract}
The article describes the experience in which the argumented parameters of the sublevel caving system in the conditions of mining operations take into account the Khibiny apatite-nepheline deposits. The stress state of the massif under the given conditions is determined by the parameters of the initial gravitational-tectonic field stresses, which have a complex distribution and redistribution for each individual isolating situation, which, in turn, is determined by the zone of the bearing pressure from the overlying stages. The necessary consideration of the factors indicated determined the order of the research: the parameters of regional field stress should be determined using the global numerical model of the deposit; after this, in order to justify the parameters of mining methods in local areas, it is necessary to make local numerical simulation for each area. All calculations were performed using Simulia Abaqus software, which implements the finite element method. Thus, the article presents numerical simulation of the stressed state of the massif of areas of "Plato Rasvumchorr" and "Apatitovii Tsirk" deposits and further describes the order of intersection of the results with the help of a global numerical model to a local numerical model of stope block at $+310 \mathrm{~m}$ at the Rusvumchorr mine. There are fixed minimum pillar sizes according to the accepted mining method in numerical simulation results using multiscale models. Key words: stress, numerical simulation, workings, pillars, rock massif
\end{abstract}

\section{Introduction.}

Existing empirical methods for calculation of pillars and the local numerical models for estimation of massif stress state unable made whole assessment of the mining-and-

*Corresponding author: Bagautdinov_II@pers.spmi.ru 
geological and mine technical situation in the region which was formed by the time of planning mining operations.

The regional numerical model of "Apatitovii Tsirk" deposit which development by Rasvumchorr mine was created for estimation of initial stress state of rock massif [1].

Geomechanical safe order of preparing of haulage level $+310 \mathrm{~m}$ by Rasvumchorr mine to excavation and reasoning primary main technical parameters of mining method was selected using local numerical model. The results of calculation the massif stress state according global numerical model was taken as boundary conditions for local numerical model.

Thus, the paper includes calculation order of safe pillar sizes and process of creating numerical models.

\section{The procedure of experimental research.}

"Apatitovii Tsirk" deposit is part of great apatite-nepheline field on South-western ore field by the Khibiny rock massif. Whole length of the ore body is 2350 meters. Dip azimuth is changing from $35^{\circ}$ to $40^{\circ}$ for north-western part and from $60^{\circ}$ to $70^{\circ}$ for south-eastern part of the deposit.

Rocks and ore on the deposit is strongly and coherent strongly with high elastic properties and sharp-crack fracture with considering their deformational and strength parameters.

The initial stress state of the rock mass on the deposit is gravitational-tectonic, with significant horizontal component.

The global numerical 3D model of "Apatitovii Tsirk" deposit was created in CAE SIMULIA Abaqus software [2]. According geological model was built wireframes of body ores, tectonic joints and their spatial location.

The analytical model of regional numerical model is shown in Fig.1. The boundary conditions of numerical model was performed as follow: the lateral faces of numerical model unable to displacement along to OX axis; the lower face unable to displacement along to OY axis; the end faces unable to displacement along to $\mathrm{OZ}$ axis; the top face of numerical model is free.

The field stress in massif is forming by own weight of rocks in vertical direction (gravitational component of field stress) and additionally by tectonic joints in horizontal direction (tectonic component of field stress).

Tuning of software Simulia Abaqus solver was adjustment as such a way as all stress in massif was compressive only. Therefore, any displacements of model top face (Earth surface) due to own weight of rocks were banned.

Whole solid space of the numerical model was separated in 482.000 three-dimensional solid elements of first order with tetrahedral form. The finite element mesh was created with differentiate by sizes. There were small finite elements around ore bodies and large finite elements at approach to boundary of numerical model. Linear sizes the faces of 
elements had size 30 meters around ore bodies and 50 meters on boundaries.

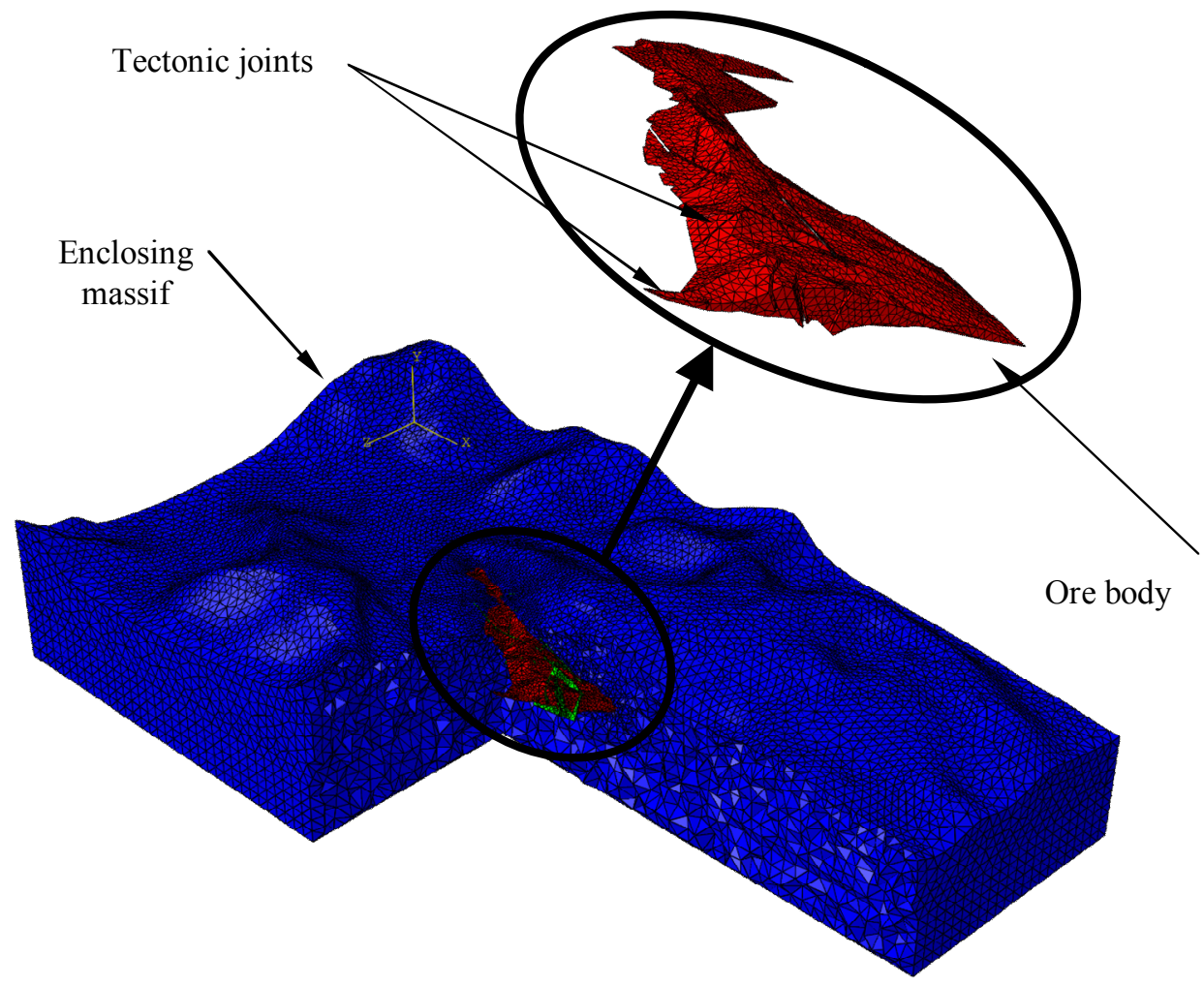

Fig 1. Analytical model with finite element mesh

The behavior of ores and rocks in enclosing massif is describing by elastic model. Deformation characteristic of massif in global numerical model was equal deformation characteristic of ores and rocks. For reason of some limits in calculation capacity and big scale the created numerical model was accepted some assumptions regard changing exist geometry of tectonic joints to some simple shapes. However, created tectonic joints were similar to exist in nature. The fragment of calculation results of the maximum principal stresses in the ore deposit at the time of the development of overlying levels is shown in Fig. 2.

S, Min. Principal (Avg: 75\%)

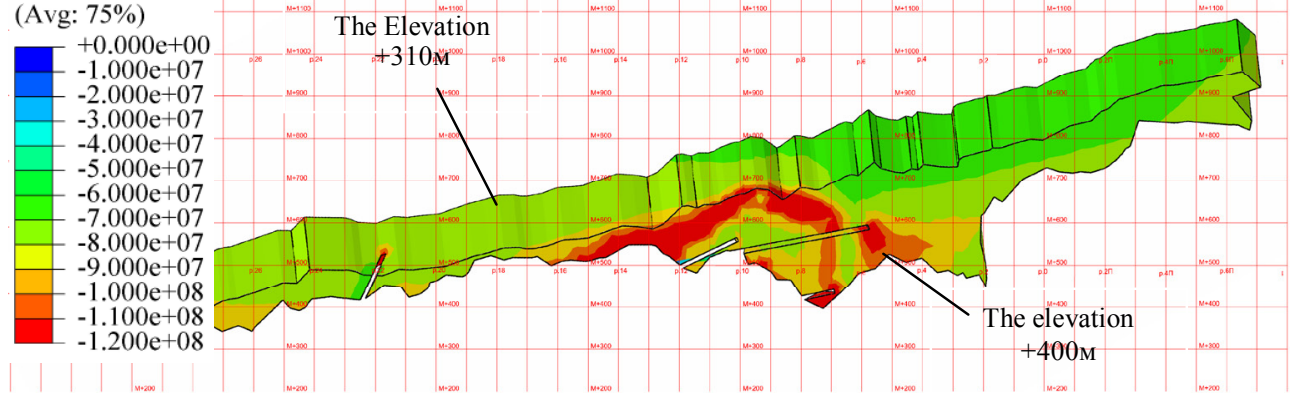

Fig 2. Maximum principal stress in the ore body after development overlying levels to the elevation $+400 \mathrm{~m}, \mathrm{~Pa}$

Analysis of the results revealed irregular distribution of maximum principal stresses in ore body both along depth and plan. The main reasons of these results are complex Earth surface and gravitational-tectonic character of distribution stresses. 
The local numerical 3D model of stope block was created in CAE SIMULIA Abaqus software. Therefore, we can forecast of stress state of massif according extraction front and other mining activity by now and near future.

As boundary conditions for local numerical model was taken the stresses of global numerical model accordance same points [3].

Thus calculated components of stress tensor for local numerical model have following details: $\sigma_{\mathrm{xx}}^{\prime}=62.5 \mathrm{MPa} ; \sigma_{\mathrm{yy}}^{\prime}=41.5 \mathrm{MPa} ; \sigma_{\mathrm{zz}}^{\prime}=10.5 \mathrm{MPa}$.

Furthermore the numerical model has following geometric details: $3500 \mathrm{~m} \times 2000 \mathrm{~m} \times$ $2000 \mathrm{~m}$ (according with direction main axes OX, OY, OZ). Beside the local numerical model has some features of stope block $7 / 10$ :

- relative space location of the three stope levels $+310 \mathrm{~m},+325 \mathrm{~m},+375 \mathrm{~m}$ in stope block $7 / 10$ according elevations and angle of slope ore body;

- boundaries of share zone with linear angle parameters such as angle of slope $\beta$ and angle of fracture $\beta^{\prime}$; an angle of slope $\beta$ determines boundaries of share zone from the side of hanging wall against low boundary of waste area;

- influence exist front extraction on stress state of massif around stope block 7/10 on level $+310 \mathrm{~m}$.

The analytical model of local numerical model is shown in Fig.3. There are main principles of sublevel caving system presented in Fig.3.

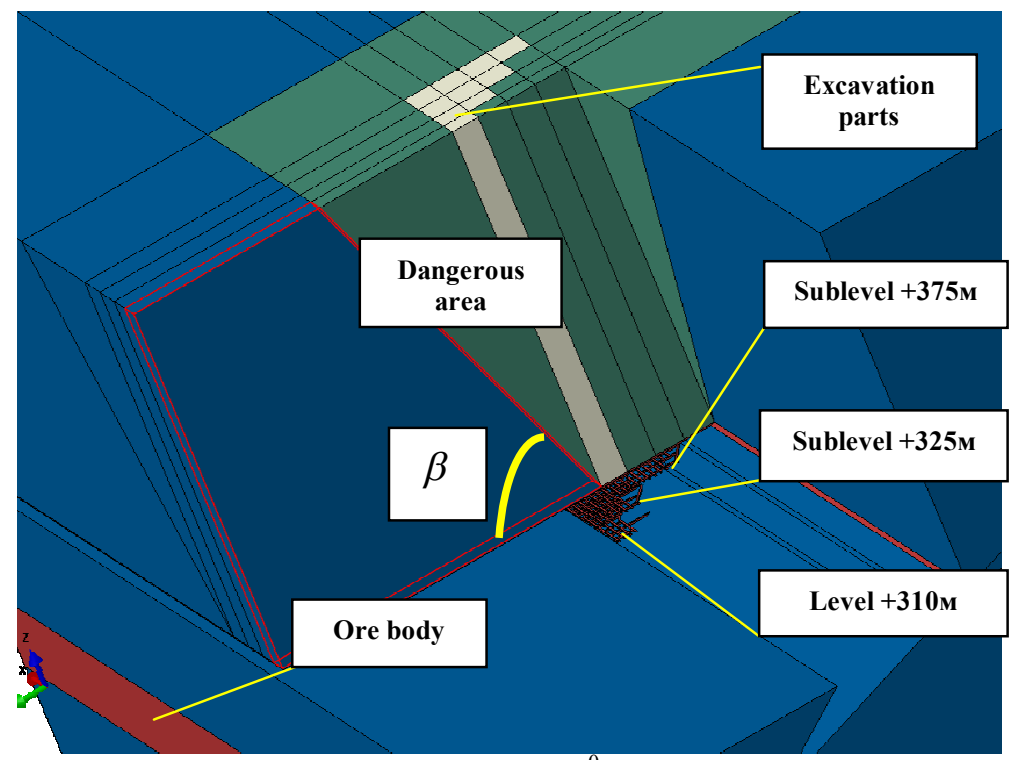

Fig 3. Analytical model: $\beta$ - angle of slope, $\beta=70^{\circ}$

\section{Results and discussion.}

Geomechanical safe sizes of pillars, height sublevel and development order of stope block was calculated by numerical simulation.

The fragment of calculation results of the minimum principal stresses in pillars wide of $13.2 \mathrm{~m}$ (3.3D, D - span of stope working) for stope level $+310 \mathrm{~m}$ with gate order development is shown in Fig. 4.

On Fig.4 you can see that displacement from hanging wall to bottom is reason for common reduction of stresses in pillars of stope level [4]. 


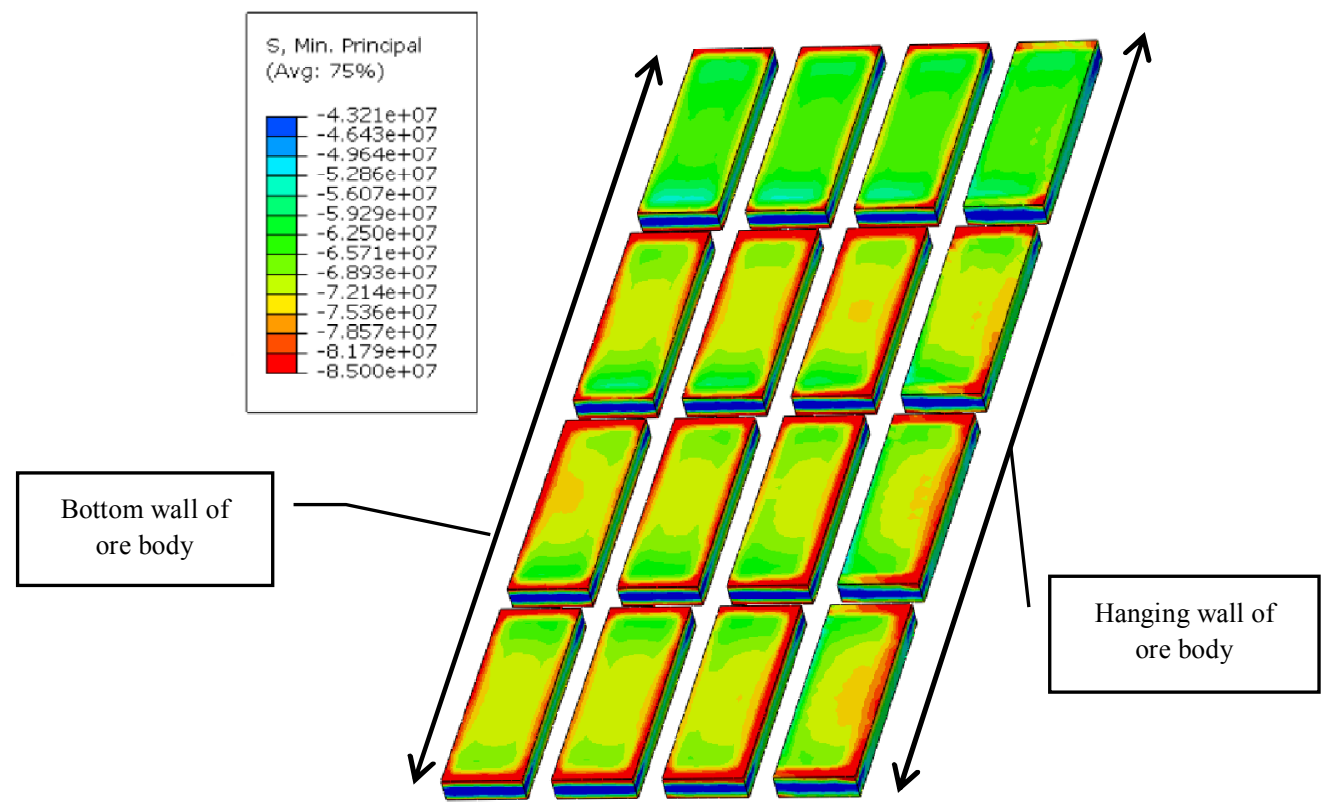

Fig 4. Maximum principal stress in pillars wide $13.2 \mathrm{~m}$ for stope level $+375 \mathrm{~m}$, Pa (gate order development)

Similar results we have using numerical modeling of pillars for width $11.2 \mathrm{~m}(2,8 \mathrm{D})$ and $15.2 \mathrm{~m}(3,8 \mathrm{D})$.

On Fig. 5 you can see chart of strength pillar dependence on it geometric sizes. Additionally in Fig.5 shown chart with maximum principal stress in pillars accordance geometric sizes.

Safe size of pillar determined as intersection both charts with considering coefficient of safety.

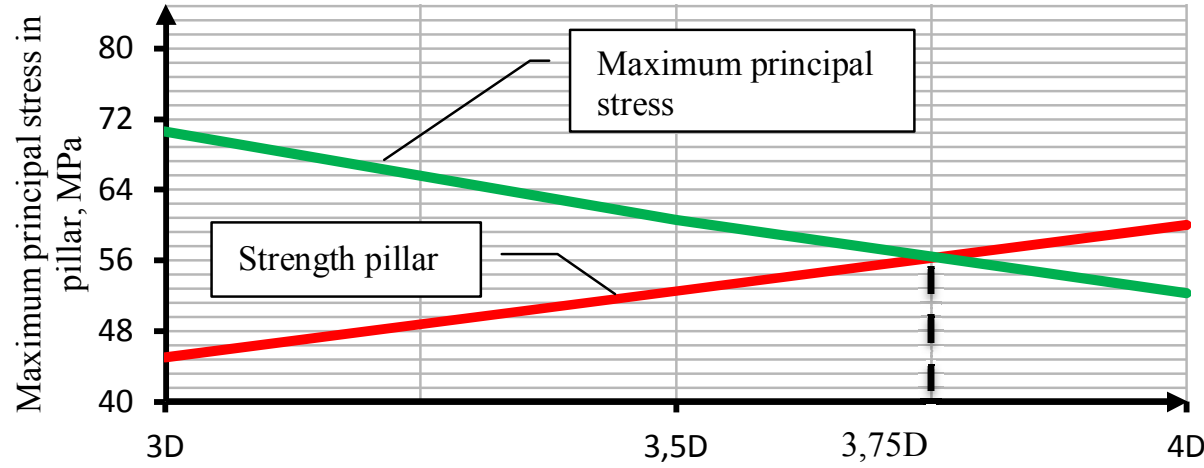

Relative pillar sizes B/H (B- pillar wide, $\mathrm{m}$; $\mathrm{H}$ - height of working, $\mathrm{H}=4 \mathrm{~m}$ )

Fig 5. Determining of safe size pillar for stope level $+375 \mathrm{~m}$ with considering coefficient of safety 


\section{Conclusions.}

The method of creating the local numerical models based on calculation results of global numerical models is important tool, which can use for geotechnical calculations with considering extraction fronts and other mining activity in deposit.

The big scale numerical model allows to take into account complex surface of mining region. Besides using numerical models may help with establish dependency degree of stress state massif from landform.

Estimation impact of tectonic joints on stress state massif around stope workings should be made based on results of geodynamic zoning using created big scale numerical model.

Along path from hanging wall of ore body to bottom wall is observed common reduction of stresses in pillars.

In this way safe pillar sizes from point of view geomechanics are determined according to results of numerical simulation using multi scale numerical models.

\section{Reference.}

1. Trout, P. L. Formulation and application of new underground mine scheduling models. PhD thesis, The University of Queensland, Brisbane, Queensland, Australia, 344pp. (1997)

2. Beck, D. A. and Duplancic, P. Forecasting performance and achieving performance indicators in high stress and seismically active mining environments. In Y. Potvin and M. Hudyma (eds.), Controlling Seismic Risk, Proceedings of the Sixth International Symposium on Rockburst and Seismicity in Mines, Perth, Western Australia, Australia, 911 March, pp. 409-417. (2005) Perth, Western Australia, Australia: Australian Centre for Geomechanics.

3. Kuranov, A.D. and Bagautdinov, I.I. Experience of geomechanical research and calculations toward ore deposit development in complex mining conditions. Geomechanics and Geodynamics of Rock Masses - Litvinenko (Ed.). Taylor \& Francis Group, London, 1037-1042 pp. (2018)

4. Lunder, P. Hard rock pillar strength estimation: An applied empirical approach. MASc thesis, University of British Columbia, Vancouver, British Columbia, Canada, 166pp. (1994) 